\title{
VALUE-AT-RISK (VAR) ANALYSIS OF THE UK BANKING STOCKS
}

\author{
DOI: 10.17261/Pressacademia.2021.1530 \\ JEFA- V.8-ISS.4-2021()-p.190-207
}

Nour Alshamali ${ }^{1}$, Khuloud M. Alawadhi ${ }^{2}$, Mansour Alshamali ${ }^{3}$, Fatemah M. Behbehani ${ }^{4}$

${ }^{1}$ Public Authority of Applied Education and Training, Insurance and Banking, Kuwait. Nm.alshamali@paaet.edu.kw, 0000-0003-4544-8100

${ }^{2}$ Public Authority of Applied Education and Training, Insurance and Banking, Kuwait. Km.alawadhi@paaet.edu.kw ,0000-0002-7993-3692

${ }^{3}$ Public Authority of Applied Education and Training, Insurance and Banking, Kuwait. Mm.alshamali@paaet.edu.kw ,0000-0003-0883-7246

${ }^{4}$ Public Authority of Applied Education and Training, Insurance and Banking, Kuwait. Fm.bahbahani@paaet.edu.kw,0000-0002-2225-8948

\section{To cite this document}

Alshamali, N., Alawadhi, K.M., Alshamali, M., Behbehani, F.M., (2021). Value-at-risk (VAR) analysis of the UK banking stocks. Journal of Economics, Finance and Accounting (JEFA), 8(4), 190-207.

Permanent link to this document: $\underline{\text { http://doi.org/10.17261/Pressacademia.2021.1530 }}$

Copyright: Published by PressAcademia and limited licenced re-use rights only.

\section{ABSTRACT}

Purpose. COVID-19's spread and worldwide efforts to contain it are having a significant influence on UK economic activity. Investor concerns about the coronavirus pandemic intensified, resulting in a decline in the value of listed shares and heightened market volatility. In this context, it is interesting to look into the considerable banking stocks in the UK to assess the risk of an investment over a set amount of time. The study's primary goal is to apply analytical and simulation VaR methodologies to five UK banking stocks, which has never been done before in the literature.

Methodology. A quantitative research design focused on data synthesis was adopted for this study. Specifically, we conducted a quantitative (VaR) analysis of five UK banking stocks, including HSBC Holdings PIc (HSBA.L), Barclays PIc (BARC.L), Standard Chartered PIc (STAN.L), Llyods Banking Group PIc (LLOY.L), and NatWest Group PIc (NWG.L), to estimate the risk of an investment portfolio. In addition to a historical VaR simulation and the variance-covariance method, we used a Monte Carlo simulation, following the GBM approach, to predict probable investment loss.

Findings. Results show that the high magnitude of VaR would be primarily due to a rise in the confidence interval (i.e., higher VaR at $99 \%$ than $95 \%$ ). Since we made no distributional assumptions, the predicted loss based on historical simulation is smaller than the other two methods. The scenarios used in VaR computation are confined to those found in the historical sample. Returns do not always follow a normal distribution in the variance-covariance approach, especially during times of crisis, causing variances and covariances to change over time. The assumption of a completely normal distribution cannot be applied to the Monte-Carlo approach.

Conclusion. This paper proposes a paradigm for analyzing portfolio performance using VaR analysis. Based on data for five UK banking equities, we revealed that the portfolio was at high risk at the start of the pandemic. The value of measuring a portfolio's VaR over time lies in both the speed with which a change in the risk profile is identified and the reflective process of analyzing why. A limitation of this research, however, is that it did not identify the maximum loss.

Keywords: VaR Analysis, historical simulation, variance-covariance, Monte-Carlo simulation, COVID-19 pandemic. JEL Codes: G21, G23, G24

\section{INTRODUCTION}

In 2007, when the big investment banks began writing down billions of dollars in mortgage-backed derivatives and other toxic instruments, it became evident that risk managers failed to protect the global financial system (Rudd, 2009). This was well before Bear Stearns went bankrupt before the government took over Fannie Mae and Freddie Mac (Frame et al., 2015).

That is before it became clear that the most significant banks and investment businesses in the United States-and, indeed, most of the Western world- were taking risks that were so absurd that they threatened to bring down the financial system itself. On the flip side, this was back when large financial firms were still telling investors that everything was fine, despite these minor setbacks - promises based, in part, on their amazingly complicated mathematical models for calculating risk in various portfolios (Saunders and Allen, 2010). There are numerous similar models, but Value-at-Risk (VaR)- is by far the most 
popular. VaR's main attraction, and its main selling point for non-quants, is that it expresses risk as a dollar figure (single number), no less (Pérignon and Smith, 2010).

Similar to the global financial crisis of 2007-2008, an unexpected event called the COVID-19 pandemic has created a financial disturbance worldwide, and the UK banking stocks are no exception. From the month before the government lockdown measures (23 March 2020), the coronavirus (COVID-19) pandemic had a massive impact on financial markets, as seen by big, unprecedented swings in UK banking stocks (ONS, 2020). The fundamental cause of all sectors' sharp, unprecedented losses in the value of listed shares on their balance sheets, culminating in the most significant fall since records began in 1987, was stock market volatility, which replicated the similar pattern observed during the 2008-2009 financial crisis (ONS, 2020). Therefore, VAR analysis should be applied to the significant UK banking stocks to estimate the risk of portfolio investments for the investors.

The objective of this study is to apply, compare and contrast various VAR analysis techniques, including the historical method, the parametric method, and the simulation method on the five UK banking stocks. The chosen stocks are HSBC Holdings Plc (HSBA.L), Barclays Plc (BARC.L), Standard Charted Plc (STAN.L), Llyods Banking Group PIc (LLOY.L), and NatWest Group Plc (NWG.L). The data is collected from Yahoo Finance for the period between 10 January 2020 to 5 August 2021. The data will be analysed using the Excel modelling technique.

More significant investor concerns about the coronavirus (COVID-19) pandemic led to a drop in the value of listed shares, resulting in increased market volatility. Due to a $25 \%$ loss in the Financial Times Stock Exchange (FTSE) 100 index, which tracks the share values of the top public businesses listed on the London Stock Exchange (LSE), UK stocks were the weakest of the significant regional equity market indices globally (ONS, 2020). The FTSE 100 index had its worst quarter in three decades, with UK company shares falling by $25 \%$ despite hitting a record high in January (ONS, 2020). This scenario makes it an interesting topic to investigate the significant banking stocks in the UK to determine the risk of an investment over a specified period of time. Therefore, the clear motivation of this study involves applying analytical and simulation VaR approaches to five UK banking stocks which have not been done in the existing literature.

Estimating a portfolio's Value-at-Risk is the subject of extensive and still-growing research. Several analytical and simulationbased techniques are available, depending on the degree of non-linearity of the instruments in the portfolio and the willingness to make stringent assumptions on the underlying statistical distributions. In its most basic form, it calculates the risk limits of a portfolio over short time periods, assuming a "normal" market. VaR is the only regularly used risk metric that can be applied to almost every asset class, which is one of the reasons it has become so popular. It also considers a bewildering array of variables, like leverage, diversification, and volatility, that make up the type of market risk that traders and organisations confront on a daily basis. As a result, the study will provide a current view of the risk concerns of the chosen UK banking stocks.

The study will contribute to the existing body of knowledge in financial research by applying the Excel modelling technique to estimate the amount of potential loss in an investment portfolio of the five chosen banking stocks. Both simulation and analytical techniques will be applied to the real data of the stocks. The results will provide a comparative view of the techniques that future researchers can use to develop new risk management models or extend the existing versions of $\mathrm{VaR}$ methods.

The paper is divided into various sections, including literature review, methodology, results, and conclusion. The literature review section will provide a critical review of the existing risk management techniques; the methodology will provide an overwise of the data collection and data analysis methods; the results section will discuss the study's findings. The conclusion section will conclude the study focusing on the outcomes of the study, limitations of the research, and future work.

\section{LITERATURE REVIEW}

The below section discusses the critical analysis of existing risk management techniques as applied by researchers in the fields of banking and finance. The articles, journals, books, and other online material will be fetched from scholarly databases like Google Scholar, IEEE, Science Direct, news websites, and government publications for this review.

\subsection{The Market Risk in Banking and the Rise of VaR}

Market risk is described as the risk of a portfolio's value depreciating due to unanticipated changes in market prices or interest rates (e.g., interest rates). Market risk affects banks in a variety of ways. A rise in interest rates, for example, might influence banks' earnings by reducing the interest margin between loans and deposits, potentially raising the risk of bad debts. Market risk also affects banks' trading portfolios; however, their exposures are determined by the institutions' hedging and risk management techniques like VaR analysis. VaR models date back to the late 1970s and early 1980s when several big financial 
organisations began developing internal models to evaluate and aggregate risks across the organisation (Dionne, 2013). Institutions began developing these models for their own risk management purposes; as firms became more global and complex, it became more difficult, but also more important, for them to aggregate their risks while accounting for how they interacted with one another, and firms lacked the methodology to do so at the time.

Rockafellar and Uryasev (2000) defined the value at risk as the loss in market value over the time horizon $\mathrm{t}$ that is surpassed with probability 1-p for a particular time horizon $t$ and confidence level $p$. The Bank for International Settlements (BIS) is a financial institution based in Switzerland that for purposes of calculating bank capital adequacy has set $p$ to 99 percent and $t$ to 10 days, albeit it would enable restricted use of the benefits of statistical diversification across different holdings and factors up the anticipated 0.01 critical value by a multiple of three (Rockafellar and Uryasev, 2000). For internal purposes, several organisations employ an overnight value at risk assessment rather than the two-week standard that is typically asked for notification to regulators, and the 99 percent confidence level is not universally used (Jorion, 1996). JP Morgan, for example, publishes its daily VaR at a 95 percent level (Jorion, 1996). Bankers Trust publishes their daily VaR at a level of 99 percent (Rockafellar and Uryasev, 2000).

Similarly, Woods et al. (2008) defined VaR as a statistical indicator of financial risk representing the portfolio's highest likely loss over a certain holding time. Because the adjective "likely" is defined in probabilistic terms, the VaR is a statistical measure. As a result, the VaR figure is dependent on two arbitrary parameters: a holding or horizon period and a probability known as the confidence level. For example, a bank's VaR on its trading portfolio might be $f 20$ million, with a confidence level of $95 \%$ and a holding term of the next trading day. This means the bank believes it has a $95 \%$ chance of making a profit or losing no more than $f 20$ million on the next trading day.

\subsection{Approaches to Estimating VaR}

The historical simulation (HS) method is the most straightforward way to calculate Value at Risk. The percentage change for each risk factor on each day is calculated using market data from the previous 250 days (Hull and White, 1998). Each percentage change is then multiplied by current market values to get 250 future value scenarios (Hull and White, 1998). The portfolio is appraised using comprehensive, non-linear pricing models for each scenario. The third-worst day is estimated to have a VaR of 99 percent.

Cabedo and Moya (2003) proposed the historical simulation approach to quantify oil prices for eight years between 1992 to 1999. The authors created a historical simulation methodology (the historical simulation with ARMA predictions approach, or HSAF), which enhances the VaR estimates supplied by the HS standard approach, as shown in figure1. Furthermore, their results indicated that the HSAF VaR predictions are more accurate than ARCH VaR estimations. However, the HSAF methodology uses the distribution of predicting errors obtained from an estimated ARMA model, rather than the distribution of actual returns.

\section{Figure1: VaR Analysis of Oil Prices}

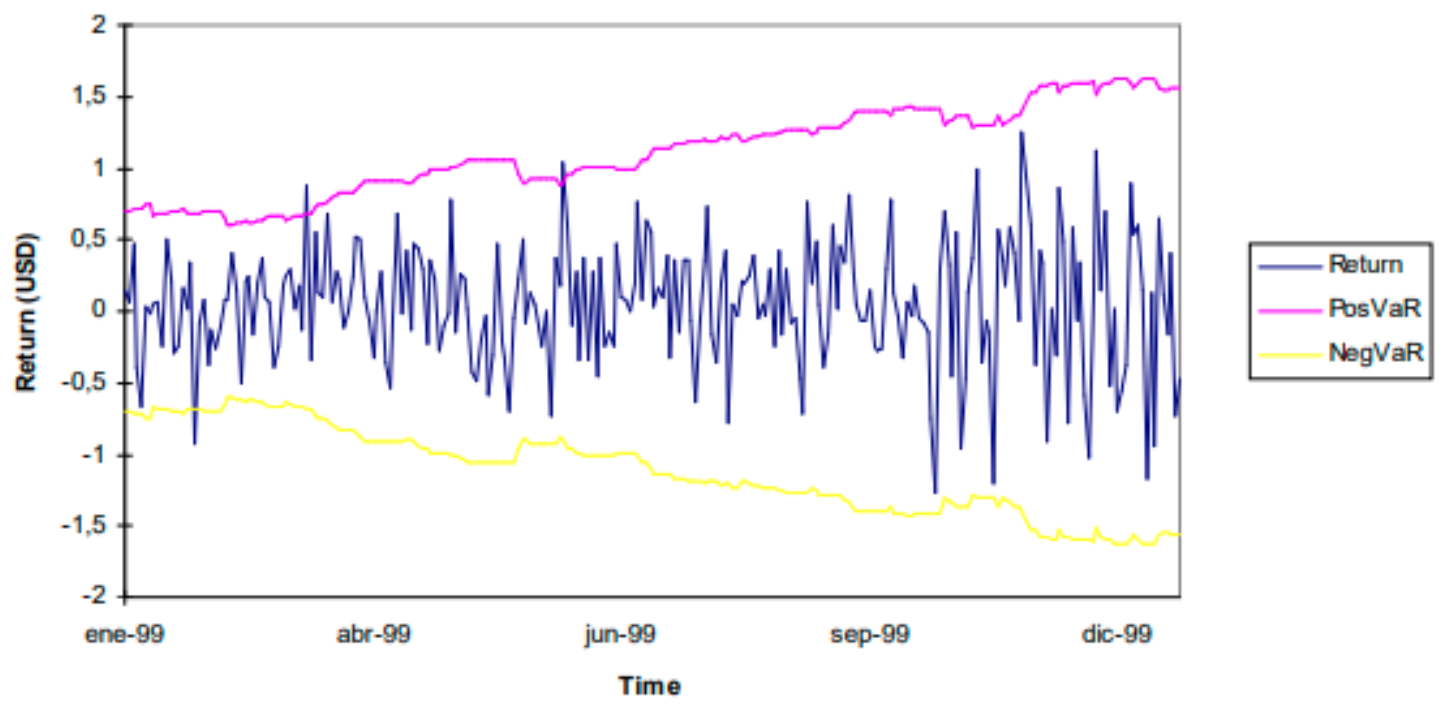

Source: Cabedo and Moya (2003) 
Normality and serial independence are not assumed in the historical simulation method. Relaxing these requirements, on the other hand, means that historical simulation systems struggle to handle translations between various percentiles and holding periods (Hendricks, 1996). Furthermore, estimating time-varying covariances and the complete covariance matrix between asset returns is critical for asset pricing, portfolio selection, and risk management, as Kroner and Ng (1998) point out. To achieve this purpose, a variety of multivariate volatility models have been developed. The diagonal GARCH model was proposed by Bollerslev et al. (1988), in which the individual variances and covariances are typical GARCH processes. Engle and Kroner (1995) have suggested the BEKK representation of the GARCH model, which makes the positive definiteness criterion on the computed covariance matrices easier to apply.

Value-at-risk (VaR) measurements, which generally show the amount of portfolio value that could be lost over a particular time period with a set confidence level, are commonly used in financial risk management. The variance-covariance method is another name for the parametric approach, which is used to estimate the risk of a portfolio. It assumes that returns follow a normal distribution. An expected return and a standard deviation must both be estimated to calculate VaR using this method.

Lopez and Walter (2000) look at the covariance matrix forecasts for a portfolio of foreign currencies. However, in both practise and research, the evaluation of VaR models has primarily focused on the frequency of exceptions, ignoring information on their magnitudes. According to Lopez and Walter (2000)'s empirical findings, covariance matrix forecasts generated from simple specifications, such as the popular EWMA specification, perform best overall inside a VaR framework. Lucas (2000) demonstrates that VaR models based on simple measurements of portfolio variance and the normal distribution produce lower disparities between actual and posited VaR values than more advanced VaR models. However, the problem of nonnormality, which is common in financial data, and the possible bias when employing parametric VaR models have dominated the VaR literature. When portfolios contain options positions, the normalcy assumption becomes problematic. Option gammas and deltas have been proposed as a mechanism to describe the convexity of the option, acting as a proxy for the nonlinear payoffs of options, to bypass this problem (Ho and colleagues, 1997).

The portfolio's return confidence interval in historical simulation methods can be calculated using historical return "scenarios" created based on a sample frequency distribution. To generate the portfolio's return frequency distribution, Monte Carlo simulations use many drawings from specified (joint) distributions. The Monte Carlo method is used to calculate the VaR by producing a random number of future rate possibilities. It is based on non-linear pricing models to estimate the change in value for each scenario and then calculate the VaR based on the worst losses (Cárdenas et al., 2001). The Monte Carlo method can be used to solve a wide range of risk measurement problems, particularly when working with several variables (Strong et al., 2009). A known probability distribution is assumed to exist for risk factors.

Because simulation approaches can effectively deal with non-linear return patterns from options and other non-linear derivative instruments, they are far more versatile than analytical methods (Hallerbach, 1999). The instruments can be marked to model, and the end-of-horizon portfolio can be determined given a specific sampling of market parameters. As opposed to Monte Carlo simulation, historical simulation has the advantage of requiring no assumptions about the underlying return generating distributions and being reasonably quick (Stambaugh, 1996). Analytical methods, on the other hand, are far more tractable and have a greater computing efficiency when there are (almost) no non-linear return patterns (Hallerbach, 1999).

\subsection{Applications of $\mathrm{VaR}$ in Banking and Finance}

The stock market has always been volatile, and it is exposed to both idiosyncratic and systemic risk. To some level, the risk is unavoidable and necessary in order to generate substantial profits. However, if it reaches a certain point, it will result in calamity. If the returns are favourable, it is not a major worry, but it has a significant impact on investors and the economy's functioning if they are negative. Researchers have devoted a lot of time and effort to studying stock market behaviour, particularly during crises.

According to Linsmeier and Pearson (2000), the creation of VaR as a risk measure was sparked by significant volatility in main economic indicators and increased usage of derivatives. It is the best risk measure for a vast class of continuous distributions, according to Gaglianone et al. (2011). After the Basel Committee on Banking Supervision made it mandatory to quantify risk using VaR in April 1995, VaR became more prominent as a risk measure in the banking sector and is now used as a base to compute the capital adequacy ratio. Barone-Adesi et al. (1999) estimated the future distribution of assets and swap values by filtering historical simulation using GARCH processes. The price changes of options were calculated via a comprehensive reevaluation of the underlying assets' changing prices. Their model considers asset correlations implicitly rather than expressly computing or constraining their values over time. VaR values for derivative securities portfolios were calculated without linearisation. Past returns were given equal probability in historical simulations, ignoring present market conditions. 
Users should choose alternate VaR models for different portfolio estimations based on the distribution, according to Sarma et al. (2003). Similarly, unrestricted VAR models were used by Tracey (2007) to uncover the leading macroeconomic indicators influencing the performance of the credit channel for Jamaica's banking sector, given the potential for banking system instability. Across all types of institutions, the model can anticipate changes in loan quality. The findings imply that monetary and structural factors influence the buildup of non-performing loans. On the other hand, worst-case scenario research finds no indication that major macroeconomic shocks would pose a systemic threat to the financial system in the next three years.

Moreover, Swamy (2014) investigated the inter-relatedness and dynamics of banking stability metrics which necessitate bank soundness, market stability, the absence of turbulence, and low volatility. Using robust panel data drawn from 56 leading banks for 12 years, the study investigated banking stability by structuring a recursive micro panel vector autoregressive (VAR) model. It corroborates the significance of the interrelatedness of bank-specific variables such as asset quality, liquidity, profitability, and capital adequacy. In China's Gold market, Chinhamu et al. (2015) looked at both gains and losses for short and long trade positions. They found that the accuracy of VaR prediction is dependent on appropriateness for extreme data observations.

On December 31, 2019, the first case of COVID-19 was reported in Wuhan, China. Later, the World Health Organization (WHO) declared it a Public Health Emergency of International Concern on January 30, 2020, even though it was not taken seriously at first (Das and Rout, 2020). With the rapid increase in the infection rate even after travel bans in China, the WHO declared it a Public Health Emergency of International Concern (Das and Rout, 2020). After this announcement, the stock market crashed and the London Stock Exchange was no exception (which makes it an interesting case study to investigate further).

The above extensive review of the literature revealed that all the three VaR approaches had been applied in banking and finance for various purposes. However, there is no evidence that VaR is calculated for the UK banking stocks. Also, none of the existing studies have compared the VaR of different methods at various confidence intervals to see how they perform in terms of risk management. The present study aims to fill this gap by computing VaR at 99 percent and 95 percent levels. Therefore, the current study will specifically fill this gap by revealing the performance of UK banking stocks in a portfolio. As mentioned, the chosen stocks are HSBC Holdings PIc (HSBA.L), Barclays Plc (BARC.L), Standard Charted PIc (STAN.L), Llyods Banking Group Plc (LLOY.L), and NatWest Group Plc (NWG.L).

\section{DATA AND METHODOLOGY}

\subsection{Data Collection and Data Analysis}

The goal of this study was to adopt a quantitative research design that focused on data synthesis. This research design was used by Glaser et al. (2014) to collect and analyse numerical data in order to create projections, look for trends and volatility, and evaluate causal links between asset prices and transaction volumes. In this regard, the current research includes a quantitative $(\mathrm{VaR})$ analysis of five UK banking stocks to estimate the risk in an investment portfolio. Furthermore, to compute VaR of the UK banking stocks, the data was collected from the Yahoo Finance database (see table1). Löeffler and Posch (2011) suggested the use of Excel for credit risk modelling.

Table 1: Chosen UK Banking Stocks

\begin{tabular}{|c|l|c|c|c|}
\hline Assets & Name of the individual assets & Ticker (LSE) & weights & f value \\
\hline Asset 1 & HSBC Holdings Plc & HSBA.L & 0.2 & 20,000 \\
\hline Asset 2 & Barclays Plc & BARC.L & 0.2 & 20,000 \\
\hline Asset 3 & Standard Charted Plc & STAN.L & 0.2 & 20,000 \\
\hline Asset 4 & Llyods Banking Group PIc & LLOY.L & 0.2 & 20,000 \\
\hline Asset 5 & NatWest Group Plc. & NWG.L & 0.2 & 20,000 \\
\hline
\end{tabular}

Additionally, Brown and Klingenberg (2015) developed an Excel model that allows the user to choose whether or not to incorporate extreme events in real estate risk modeling and the severity of these events. The study provided that to quantify risk, investment counsellors no longer require costly add-ons. The Excel model provided is more robust than other approaches since it considers distribution shapes that are not readily available (Brown and Klingenberg, 2015). The one obvious constraint is that users must be conversant with Excel's most basic functions.

Excel software was used to analyse the data from 10 January 2020 (approximate beginning of the COVID-19 pandemic) to 5 August 2021. To extract insights from the data, Excel's statistical algorithms and data visualisation capabilities were used (Barreto, 2015). Excel modeling enables scenario planning by simulating the effect of critical variables, allowing for the proper course of action to be taken in various future scenarios (Mason, 2013). 


\subsection{VaR Methods}

For the study under consideration, a portfolio of five UK banking stocks was constructed by using three different methodsthe Historical Simulation method, the Variance-Covariance method, and the Monte Carlo Simulation Method. The total value of the portfolio is taken to be $f 100,000$, where each asset weighs $20 \%$, investing $£ 20,000$ in each asset. The chosen assets are HSBC Holdings PIc (HSBA.L), Barclays PIc (BARC.L), Standard Charted Plc (STAN.L), Llyods Banking Group PIc (LLOY.L), and NatWest Group Plc (NWG.L). Based on 99\% and 95\% confidence intervals and 397 trading days (between 1-10-2020 to 0508-2021), VaR of the portfolio was computed using three different methods as follows:-

- Historical Simulation method: The amount of investment loss is calculated using the closing prices of the assets (collected from Yahoo Finance) in the historical simulation technique.

- Variance-covariance method: The variance-covariance approach is a parametric risk management technique that calculates a portfolio's VaR using the mean and standard deviation (Aninas et al., 2009), as shown in formula 1 below.

The variance-covariance approach to calculate $\mathrm{VaR}$ was calculated based on the following formula:

$V a R_{p}=\left(V C V^{T}\right)^{1 / 2}$

where $\mathrm{V}$ is the row vector of VaRs for each individual position, $\mathrm{C}$ is the matrix of correlations, $V^{T}$ is the transpose of matrix $\mathrm{V}$ (Čorkalo, 2011).

Monte Carlo Simulation method: The George Brownian Motion (GBM) approach was used in the study under discussion. In a Geometric Brownian Motion (GBM) model (see figure3), the logarithm of a randomly fluctuating quantity follows a Brownian motion (also known as the Wiener method), according to Estember and Maraa (2016). Despite the fact that the GBM model requires a significant number of calculations (i.e., limitation) to interpret correct results, it delivers an accurate value for actual losses (Abidin and Jaffar, 2012). As a result, GBM is the most potent model for predicting probable investment loss (Abidin and Jaffar, 2012).

The GBM approach to calculate VaR has been illustrated in equation (2) below based on the study by Cheung and Powel (2012):

$\Delta S=S(\mu \Delta t+\sigma e \sqrt{\Delta t})$

where $\Delta S$ is the change in portfolio value, $\mathrm{S}$ is the portfolio value, $\mu$ is the expected return per unit of time, $\Delta t$ is the elapsed time period, $\sigma$ is the volatility or standard deviation of returns, e is the random variable with a standard normal distribution, $\mu \Delta t$ is the drift and $\sigma e \sqrt{\Delta t}$ represents shock.

To estimate drift + shock (pseudo-returns), the steps used include daily returns of all assets, estimation of constant parameters, price paths, calculation of drift + shock.

\section{FINDINGS AND DISCUSSIONS}

The results computed by using all VaR methods are discussed in the section below.

\subsection{Historical Simulation Method}

Based on 397 simulated values, the VaR of five UK banking stocks was computed (Appendix1). The returns of all the assets in the portfolio were computed by using Excel's LN function, as shown in figure2. After that, the portfolio return was determined by multiplying the weight of each asset by its daily return. 
Figure 2: LN Function to Calculate Assets' Returns

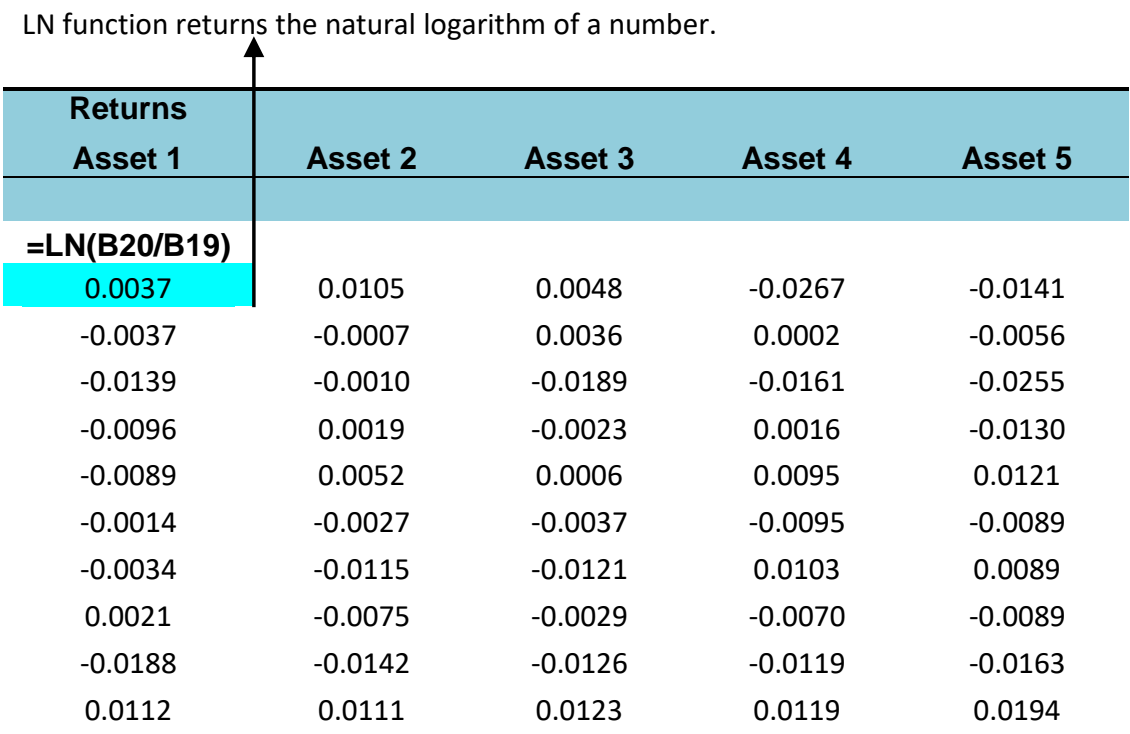

The next step is to sort the simulated values (from lowest to highest profit/loss) in ascending order. Finally, as shown in figure3, historic VaR was determined by multiplying $f 100000$ (portfolio sum) by the ordered simulated values. The same steps were repeated to obtain VaR at a 95\% confidence interval, as shown in figure4.

Figure 3: Computation of Historic VaR at $99 \%$ Confidence Interval

\begin{tabular}{rrr}
\multicolumn{1}{c}{$\begin{array}{c}\text { VaR } \\
\text { (historic) }\end{array}$} & $\begin{array}{c}\text { VaR } \\
\text { at } 99 \%\end{array}$ \\
\cline { 1 - 2 }-510.19017 & & \\
-49.82994 & & \\
-1229.69889 & & \\
-236.75103 & -236.7510326 & P23= No. of observations \\
546.91014 & & M8= position of historic VaR \\
-496.05258 & & Q23= amount of historic VaR \\
-87.56348 & & \\
-528.28530 & & \\
-1100.32274 & \\
1095.24240 &
\end{tabular}


Figure 4: VaR at $95 \%$ Confidence Interval

\begin{tabular}{rrr}
$\begin{array}{c}\text { No of } \\
\text { obs. }\end{array}$ & $\begin{array}{c}\text { VaR } \\
\text { (historic) }\end{array}$ & $\begin{array}{c}\text { VaR } \\
\text { at 95\% }\end{array}$ \\
\hline 1 & - & \\
2 & -410.19 & \\
16 & -66.7692 & \\
17 & 1311.32 & \\
18 & 100.532 & \\
19 & 306.258 & \\
20 & 36.0642 & \\
21 & -439.232 & \\
22 & 868.515 & \\
23 & 828.332 & \\
24 & -145.692 & \\
25 & -2060.89 & \\
26 & -85.8696 & \\
27 & -2057.4 & \\
28 & -7.39905 & \\
29 & 303.262 & \\
&
\end{tabular}

Excel's ROUND function was used to return the position of VaR, as shown in figure5. The VaR using the historical simulation technique is $f 246.75$, as shown in figure5, based on 397 trading days (between 1-10-2020 and 5-08-2021) with a 99 percent confidence interval or probability=0.01. It means that the portfolio will not lose more than $£ 246.75$ at a $99 \%$ confidence interval. Similarly, with a 95 percent confidence interval or probability $=0.05$, the $\mathrm{VaR}$ of the portfolio under consideration is f36.06 (i.e., the maximum loss).

Figure 5: Position of VaR at a $95 \%$ Confidence Interval

\begin{tabular}{|c|c|}
\multicolumn{1}{c|}{ Historic Simulation } & Value \\
\hline Particulars & 0.05 \\
\hline Prob. for VaR calculation & 0.95 \\
\hline Level of Certainty & 397 \\
\hline Number of observations & 20 \\
\hline Historic VaR is at position & It has happened on 7-02-2020. \\
\hline
\end{tabular}

Note: The Historic VaR is calculated as the rounding of the product between the probability for VaR calculation and the number of observations

\subsection{Variance-Covariance Method}

Using this method, the standard deviation of each asset was calculated by using the 'STDEV' function in Excel. Then, each asset's individual VaR was computed at $99 \%$ and $95 \%$ confidence intervals. Individual VaR is a product of the value of asset and normal distribution value and standard deviation as shown in table2, figure6, and figure7.

Figure 6: Individual VaR

\begin{tabular}{|c|c|c|c|c|}
\hline Assets & Value of Asset & Std. Dev. & VaR@99\% & VaR@95\% \\
\hline 1 & 20000 & 0.03267698744 & 1520.360806 & 1074.977225 \\
\hline 2 & 20000 & 0.02258277271 & 1050.707706 & 742.9071113 \\
\hline 3 & 20000 & 0.02759776902 & 1284.040226 & 907.8858082 \\
\hline 4 & 20000 & 0.02896458321 & 1347.633932 & 952.8499939 \\
\hline 5 & 20000 & 0.02959045224 & 1376.753713 & 973.4392527 \\
\hline
\end{tabular}


Table 2: VaR Using Variance-Covariance Method

$\begin{array}{lc}\text { Level of Certainty } & 0.95 \\ \text { Normal dist. Value } & 1.645 \\ & \\ \text { Worse Case VaR } & 4,652 \\ \text { VaR } & 4,209\end{array}$

Figure 7: Individual VaR of the UK Banking Stocks at 99\% and 95\% Confidence Intervals

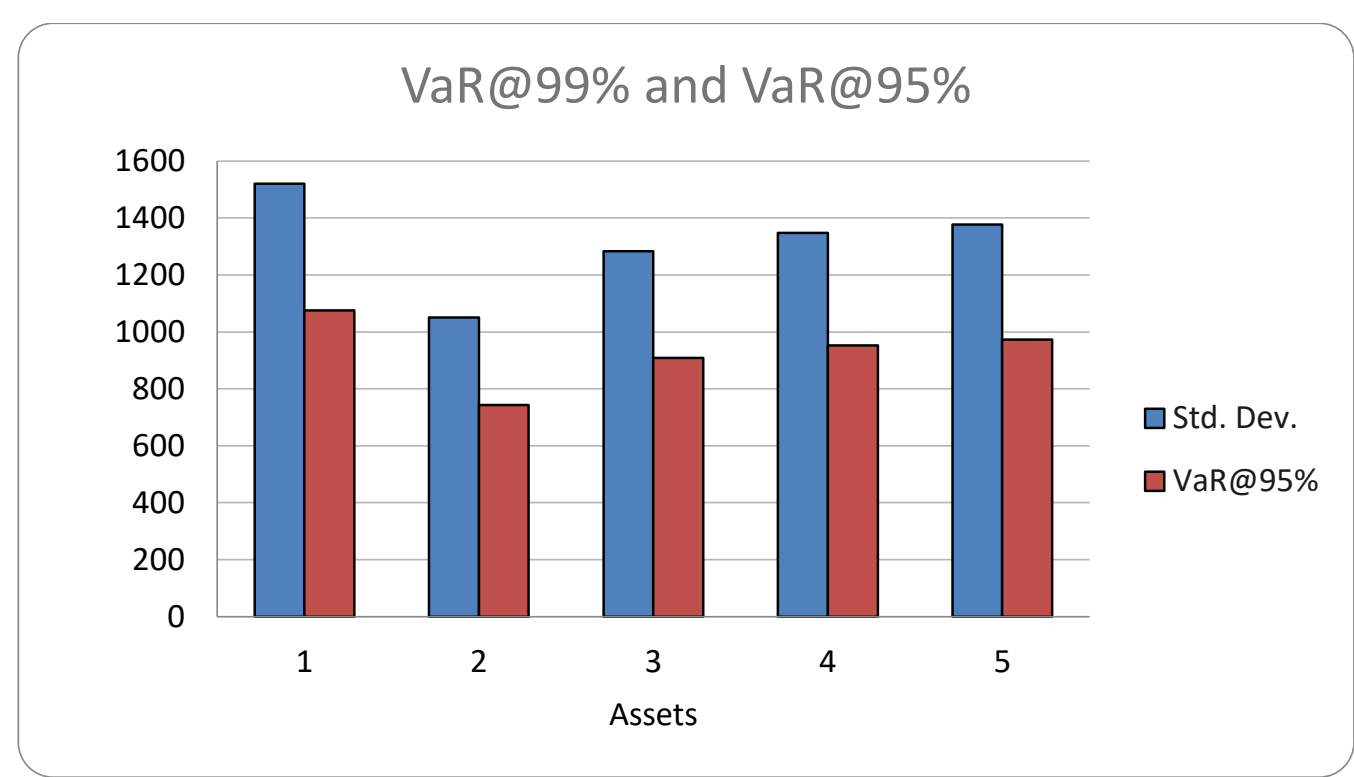

Furthermore, a correlation matrix was created to calculate the portfolio's VaR (see table3 and table4). Then the 'MMULT' function (which returns the product of the two arrays) was used to obtain the VaR of $£ 5,933$ at $99 \%$ confidence interval and $£ 4,209$ at $95 \%$ confidence interval, implying that as there is a $1 \%$ probability that the portfolio will lose more than $£ 5,933$ and there is a $5 \%$ probability that the portfolio will lose more than $£ 4,209$.

Table 3: Correlation Matrix at $99 \%$ Confidence Interval

\begin{tabular}{|c|c|c|c|c|c|}
\hline & \multicolumn{5}{|c|}{ Correlation Matrix } \\
\cline { 2 - 6 } & HSBA.L & BARC.L & STAN.L & LLOY.L & NWG.L \\
\hline HSBA.L & 1.000 & 0.684 & 0.760 & 0.864 & 0.817 \\
\hline BARC.L & 0.684 & 1.000 & 0.787 & 0.680 & 0.655 \\
\hline STAN.L & 0.760 & 0.787 & 1.000 & 0.732 & 0.733 \\
\hline LLOY.L & 0.864 & 0.680 & 0.732 & 1.000 & 0.873 \\
\hline NWG.L & 0.817 & 0.655 & 0.733 & 0.873 & 1.000 \\
\hline $\begin{array}{c}\text { Each asset's } \\
\text { Individual VaR }\end{array}$ & $\mathbf{1 5 2 0 . 3 6 1}$ & $\mathbf{1 0 5 0 . 7 0 8}$ & $\mathbf{1 2 8 4 . 0 4 0}$ & $\mathbf{1 3 4 7 . 6 3 4}$ & $\mathbf{1 3 7 6 . 7 5 4}$ \\
\hline
\end{tabular}


Table 4: Correlation Matrix at $95 \%$ Confidence Interval

\begin{tabular}{|c|c|c|c|c|c|}
\hline & \multicolumn{5}{|c|}{ Correlation Matrix } \\
\cline { 2 - 6 } & HSBA.L & BARC.L & STAN.L & LLOY.L & NWG.L \\
\hline HSBA.L & 1.000 & 0.690 & 0.763 & 0.869 & 0.827 \\
\hline BARC.L & 0.690 & 1.000 & 0.794 & 0.689 & 0.668 \\
\hline STAN.L & 0.763 & 0.794 & 1.000 & 0.737 & 0.742 \\
\hline LLOY.L & 0.869 & 0.689 & 0.737 & 1.000 & 0.877 \\
\hline NWG.L & 0.827 & 0.668 & 0.742 & 0.877 & 1.000 \\
\hline $\begin{array}{c}\text { Each asset's } \\
\text { Individual VaR }\end{array}$ & $\mathbf{1 0 7 4 . 9 7 7}$ & $\mathbf{7 4 2 . 9 0 7}$ & $\mathbf{9 0 7 . 8 8 6}$ & $\mathbf{9 5 2 . 8 5 0}$ & $\mathbf{9 7 3 . 4 3 9}$ \\
\hline
\end{tabular}

Moreover, worst-case VaR (the expected shortfall) was also calculated, as shown in Table5.

Table 5: Worst-Case VaR using Variance-Covariance Method

\begin{tabular}{|c|c|}
\hline \multicolumn{2}{|c|}{ Comparison of Worst-case VaR at various intervals } \\
\hline Confidence Intervals & Worse Case VaR \\
\hline$@ 90 \%$ & $£ 6,579$ \\
\hline$@ 95 \%$ & $£ 4,652$ \\
\hline
\end{tabular}

\subsection{Monte Carlo Simulation Method}

2000 simulations were performed (Appendix2), and the LN function in Excel was used to compute the historical returns. In the next step, constant parameters were obtained at $99 \%$ confidence interval, as shown in figure 8 . The same process was repeated to get constant parameters at $95 \%$ confidence interval.

Figure 8: Constant Parameters

\begin{tabular}{|l|c|l|}
\hline Particulars & Value & Formula used \\
\hline Portfolio Value & 50000 & - \\
\hline Time Increment & 0.002404 & $\mathrm{fx}=1$ /number of trading days \\
\hline Average daily return & -0.000452 & $\mathrm{fx}=$ Average(Range of returns) \\
\hline Annualized return & -0.164157 & $\mathrm{fx}=(1+$ average daily return)^397-1 \\
\hline Average daily SD & 0.025503 & $\mathrm{fx}=\mathrm{STDEV(Range} \mathrm{of} \mathrm{returns)}$ \\
\hline Annualized STD & 0.508135 & $\mathrm{fx}=$ Average daily std dev*SQRT(397) \\
\hline Expected return & -0.293258 & $\mathrm{fx}=$ annualized daily return-((annualized std $\left.\left.\operatorname{dev}^{\wedge} 2\right) / 2\right)$ \\
\hline
\end{tabular}

The RAND() function was used to generate the random numbers as per the GBM method (see figure 9 and figure10), and the NORMSINV() function was used to obtain the opposite of the cumulative uniform normal distribution (Appendix3). 
Figure 9: Rand() at 397 Trading Days

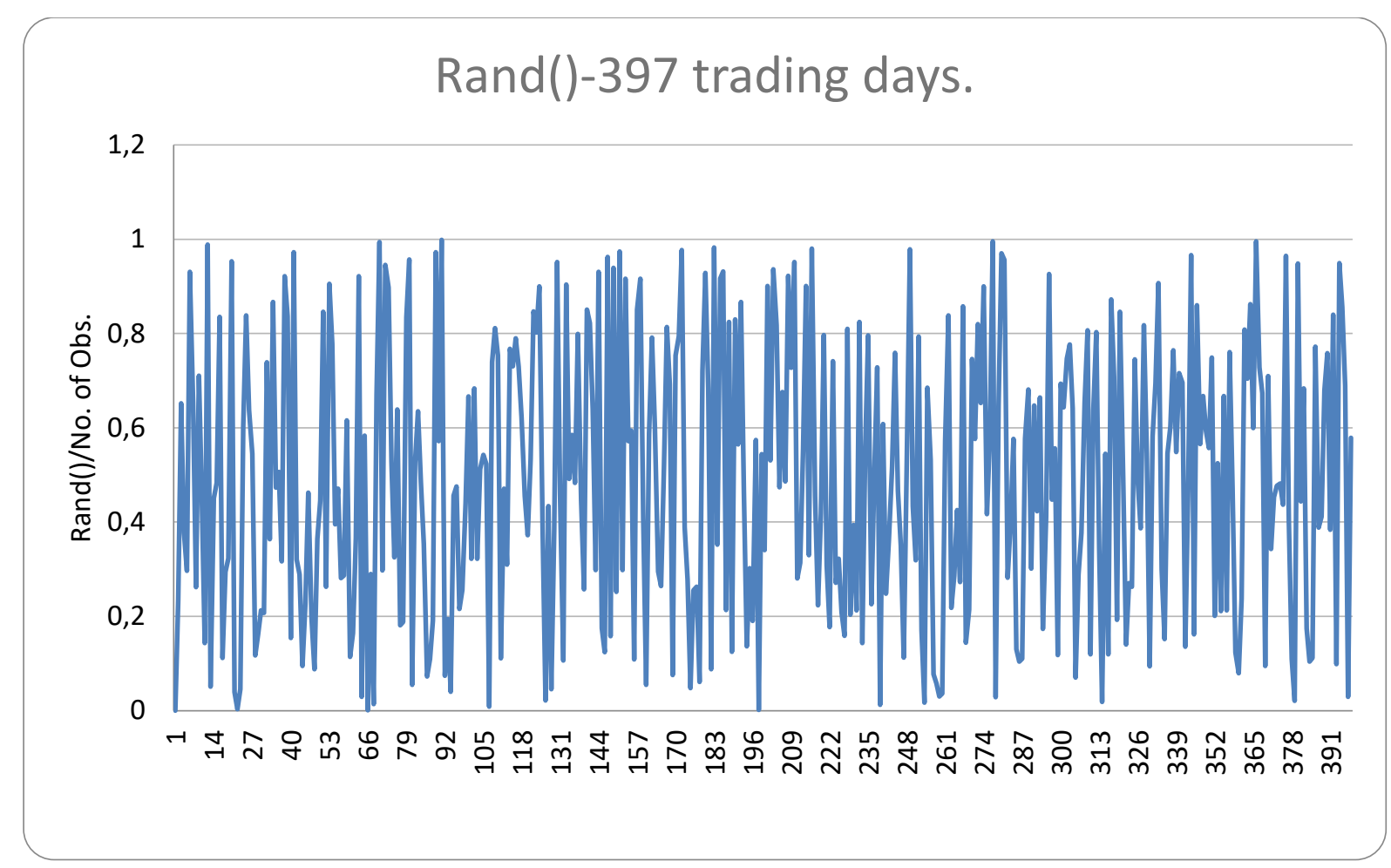

Figure 10: RAND() at 2000 Simulations

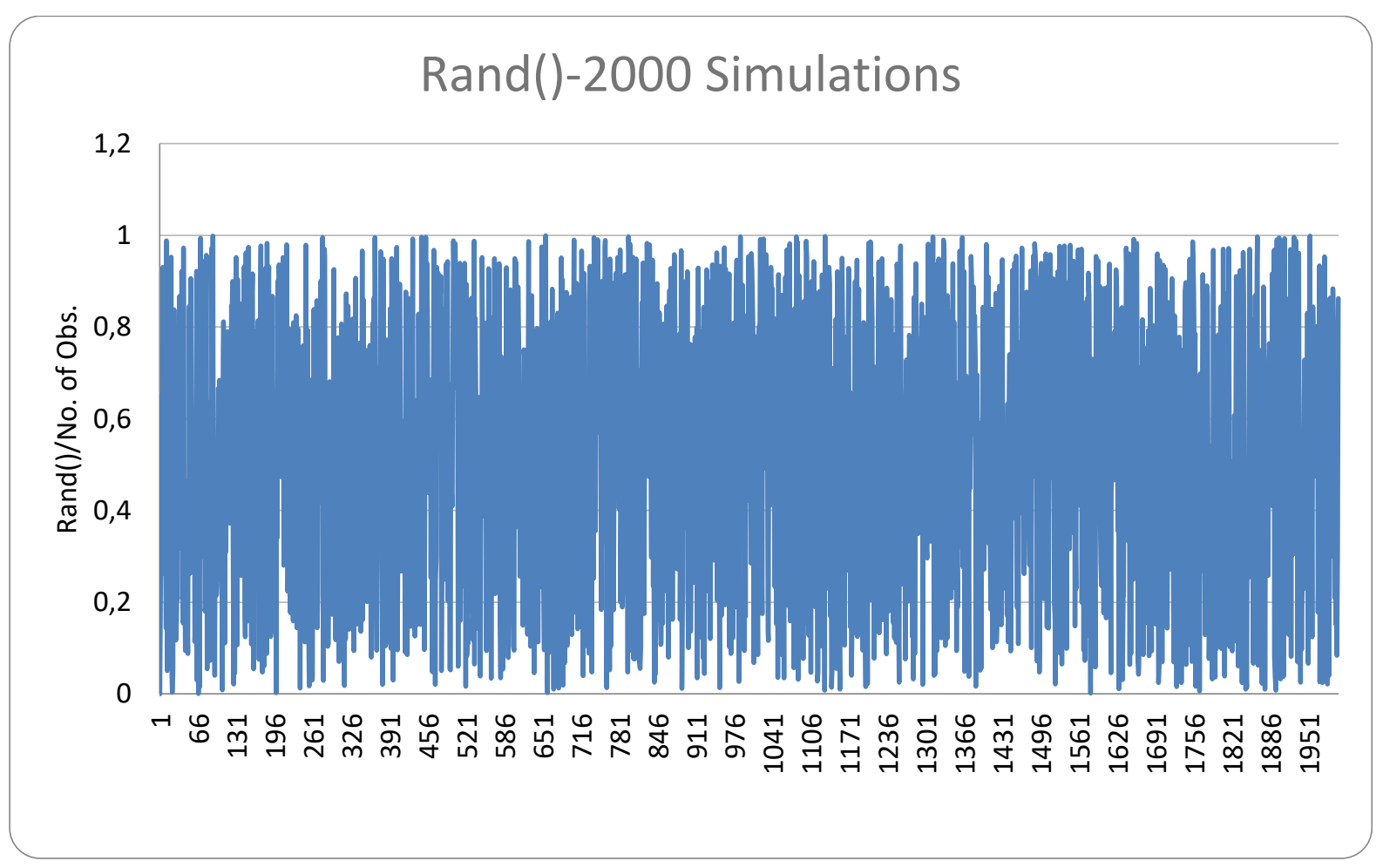


Then, pseudo-returns were calculated based on a normal distribution (see figure11) and the VaR at $99 \%$ was estimated at $f 5,710$, which means that the portfolio will not lose more than $f 5,710$. The same process was repeated to obtain VaR at $95 \%$, which is estimated at $£ 1,950$ which means that the portfolio will not lose more than $£ 1,950$.

\section{Figure 11: Calculation of Pseudo-Returns}

\begin{tabular}{ccc} 
& & $\mathrm{IF}(\mathrm{N} 23=\$ \mathrm{~K} \$ 8, \mathrm{R} 23, " ')$ \\
\hline $\begin{array}{c}(\mu \Delta t+\sigma e V \Delta t) \\
\text { Pseudo Return }\end{array}$ & \multicolumn{1}{c}{$\boldsymbol{\Delta}$} & $\begin{array}{c}\text { VaR } \\
\text { at } 99 \%\end{array}$ \\
\hline 0 & \multicolumn{1}{c}{0} & - \\
0.015142832 & 1514.283165 & \\
-0.007929862 & -792.9862256 & \\
0.012124243 & 1212.424348 & 5709.292214 \\
0.057092922 & 5709.292214 & \\
-0.030250833 & -3025.083345 & \\
0.017807493 & 1780.749257 & \\
-0.03872752 & -3872.752021 & \\
-0.017978216 & -1797.8216 & \\
-0.003835833 & -383.5833162 & \\
0.026112346 & 2611.234559 & \\
0.022374613 & 2237.461279 & \\
-0.042191277 & -4219.1277 & \\
0.022835836 & 2283.583627 & \\
0.020841561 & 2084.156109 &
\end{tabular}

\subsection{Discussion}

The study's findings revealed that due to an increase in the confidence interval, the magnitude of VaR would be high, i.e., high VaR at $99 \%$ than $95 \%$, as presented in table6.

The estimated loss based on the historical simulation is lower than the other two methods because this method makes no distributional assumptions; the situations utilised in VaR computation are limited to those found in the historical sample (Čorkalo, 2011). Furthermore, in the case of historical simulation, the chance of severe events occurring is only relevant if the data is recent.

Table 6: VaR Employing All Methods

\begin{tabular}{|l|c|c|}
\hline \multirow{2}{*}{ Methods } & \multicolumn{2}{|c|}{ Confidence Intervals } \\
\hline Historical Simulation & at $\mathbf{9 9 \%}(\mathbf{f})$ & at $\mathbf{9 5 \%}(\mathbf{f})$ \\
\hline Variance-Covariance & 246.76 & 36.06 \\
\hline Monte Carlo Simulation & 5,933 & 4,209 \\
\hline
\end{tabular}

In the case of the variance-covariance method, returns, particularly in times of crisis, do not always follow a normal distribution, which can cause variances and covariances to fluctuate over time.

Because the distribution of risk factors is expected, the possibility of capturing extreme events is low when using the variancecovariance method. Furthermore, because all distributions have skewness and kurtosis, the assumption of a completely normal distribution cannot be applied to the Variance-Covariance method and the Monte-Carlo approach (Homem-de-Mello and Bayraksan, 2014).

\section{CONCLUSION AND IMPLICATIONS}

Portfolio managers are frequently subjected to severe constraints as a result of the recent financial crisis and the tightening of regulatory processes, which have complicated repercussions for their performance. This study presents a framework for 
analysing portfolio performance using a statistical metric known as VaR analysis. The study of five UK banking stocks provided that the stocks remained quite volatile during the pandemic. To meet the objective of the study, models were built using Excel software. The findings of the study suggested that the portfolio was at high risk between 16 January 2020 and 7 February 2020 (i.e., at the start of the pandemic). The highest expected loss is $£ 5,933$, and the lowest is $£ 36.06$. The usefulness of tracking a portfolio's VaR over time is found in both the quickness with which a change in the risk profile is detected and the reflective process of determining why. However, the analysis did not tell about the maximum loss (the computed values reveal the minimum loss only). For instance, using the MCS method, VaR at $99 \%$ was estimated to be $f 5,710$, which means that the minimum loss will not be more than $£ 5,710$, i.e., it is not clear that if the maximum loss will be $f 5,800, £ 5,900, £ 6,000$ or beyond.

VaR only informs us how much an investor can lose if a tail event does not happen (for example, how much an investor can lose 99 percent of the time), but it does not tell portfolio managers how much investors can lose in the remaining $1 \%$ of cases. As a result, a trader or asset manager could 'spike' his firm or clients by engaging in transactions that create minor returns in most cases and significant losses on rare occasions. If the risk of loss is low enough, the position will have a low VaR and hence appear to be low risk, but the firm or clients will now be exposed to the potential of a huge loss.

Because VaR is a 'backward looking' statistic, it has limitations in terms of its efficacy. VaR can be a risky instrument in a prolonged period of historically low volatility. Backtesting a position's risk with such data can lead to a false sense of security. Another factor to consider is that VaR estimations are frequently inaccurate, and empirical evidence in this study reveals that different VaR models can produce dramatically different VaR estimates (see table6). VaR models are also subject to a great deal of implementation risk, which means that, even in theory, similar models could produce dramatically different VaR estimates due to changes in how the models are implemented in practise. The risk here is obvious: if VaR estimates are overly wrong, financial statement users may be exposed to far greater risks than they paid for.

To address the above-mentioned weaknesses and limitations of the current study, future researchers can utilize data mining techniques to compute $\mathrm{VaR}$ of real-time data. Data mining also entails developing linkages and identifying anomalies, patterns, and correlations in order to solve problems and generate actionable data. It will assist asset managers in making educated decisions by immediately beginning automatic behavioural and trend predictions and uncovering hidden patterns.

\section{REFERENCES}

Aniūnas, P., Nedzveckas, J. and Krušinskas, R. (2009). Variance-covariance risk value model for currency market. Engineering economics, 61(1), 1-5.

Abidin, S.N.Z. and Jaffar, M.M. (2012). A review on Geometric Brownian Motion in forecasting the share prices in Bursa Malaysia. World Applied Sciences Journal, 17(1), 82-93.

Barone-Adesi, G., Giannopoulos, K. and Vosper, L. (1999). VaR without correlations for portfolios of derivative securities. Journal of Futures Markets, 19(5), 583-602.

Barreto, H. (2015). Why Excel?. The Journal of Economic Education, 46(3), 300-309.

Bollerslev, T., Engle, R.F. and Wooldridge, J.M. (1988). A capital asset pricing model with time-varying covariances. Journal of political Economy, 96(1), 116-131.

Brown, R. and Klingenberg, B. (2015). Real estate risk: Heavy tail modelling using Excel. Journal of Property Investment \& Finance, 33(4), 393407.

Cabedo, J.D. and Moya, I. (2003). Estimating oil price 'Value at Risk' using the historical simulation approach. Energy economics, 25(3), 239253.

Cárdenas, J.D., Fruchard, E., Picron, J.F., Reyes, C., Walters, K. and Yang, W. (2001). Monte Carlo within a day. In Quantitative Analysis In Financial Markets: Collected Papers of the New York University Mathematical Finance Seminar, Vol.II, 335-345.

Cheung, Y.H. and Powell, R.J. (2012). Anybody can do value at risk: a teaching study using parametric computation and Monte Carlo simulation. Australasian Accounting, Business and Finance Journal, 6(5), 101-118.

Čorkalo, Š. (2011). Comparison of value at risk approaches on a stock portfolio. Croatian Operational Research Review, 2(1), 81-90.

Das, N.M. and Rout, B.S. (2020). Impact of COVID-19 on Market Risk: Appraisal with Value-at-risk Models. The Indian Economic Journal, 68(3), 396-416.

Dionne, G. (2013). Risk management: History, definition, and critique. Risk management and insurance review, 16(2), $147-166$.

Engle, R.F. and Kroner, K.F. (1995). Multivariate simultaneous generalized ARCH. Econometric theory, 11(1), 122-150. 
Estember, R.D. and Maraña, M.J.R. (2016). March. Forecasting of Stock Prices Using Brownian Motion-Monte Carlo Simulation. In Proceedings of the 2016 International Conference on Industrial Engineering and Operations Management. [online] Kuala Lumpur, Malaysia, p.2. Available at: <http://ieomsociety.org/ieom_2016/pdfs/192.pdf> [Accessed 19 September 2021].

Gaglianone, W.P., Lima, L.R., Linton, O. and Smith, D.R. (2011). Evaluating value-at-risk models via quantile regression. Journal of Business \& Economic Statistics, 29(1), 150-160.

Hallerbach, W.G. (1999). Decomposing portfolio value-at-risk: A general analysis (No. 99-034/2). Tinbergen Institute Discussion Paper.

Hendricks, D. (1996). Evaluation of value-at-risk models using historical data. Economic policy review, 2(1), 1-32.

Ho, T.S., Chen, M.Z. and Eng, F.H. (1996). VAR analytics: Portfolio structure, key rate convexities, and VAR betas. Journal of portfolio management, 23(1), 89-101.

Homem-de-Mello, T. and Bayraksan, G. (2014). Monte Carlo sampling-based methods for stochastic optimization. Surveys in Operations Research and Management Science, 19(1), 56-85.

Hull, J. and White, A. (1998). Incorporating volatility updating into the historical simulation method for value-at-risk. Journal of Risk, 1(1), 519.

Frame, W.S., Fuster, A., Tracy, J. and Vickery, J. (2015). The rescue of fannie mae and freddie mac. Journal of Economic Perspectives, 29(2), 25-52.

Glaser, F., Zimmermann, K., Haferkorn, M., Weber, M.C. and Siering, M. (2014). Bitcoin-asset or currency? Revealing Users' Hidden Intentions. In: Twenty Second European Conference on Information Systems. [online] pp.2-14. Available at: $<$ https://www.researchgate.net/profile/Florian-Glaser/publication/286338705_Bitcoin_-

_Asset_or_currency_Revealing_users'_hidden_intentions/links/5a1bbbb2aca272df080f2f07/Bitcoin-Asset-or-currency-Revealing-usershidden-intentions.pdf> [Accessed 19 September 2021].

Kroner, K.F. and Ng, V.K. (1998). Modeling asymmetric comovements of asset returns. The review of financial studies, 11(4), 817-844.

Jorion, P. (1996). Risk2: Measuring the risk in value at risk. Financial analysts journal, 52(6), 47-56.

Linsmeier, T.J. and Pearson, N.D. (2000). Value at risk. Financial Analysts Journal, 56(2), 47-67.

Löeffler, G. and Posch, P.N. (2011). Credit risk modeling using Excel and VBA. John Wiley \& Sons.

Lopez, J.A. and Walter, C.A. (2000). Evaluating covariance matrix forecasts in a value-at-risk framework. FRB of San Francisco Working Paper, (2000-21).

Lucas, A. (2000). A note on optimal estimation from a risk-management perspective under possibly misspecified tail behavior. Journal of Business \& Economic Statistics, 18(1), 31-39.

Mason, A.J. (2013). SolverStudio: A new tool for better optimisation and simulation modelling in Excel. INFORMS Transactions on Education, 14(1), 45-52.

ONS. (2020). Early assessment of the impact of the coronavirus pandemic on the UK's financial accounts - Office for National Statistics. [online] Ons.gov.uk. Available at:

<https://www.ons.gov.uk/economy/nationalaccounts/uksectoraccounts/articles/earlyassessmentoftheimpactofthecoronaviruspandemico ntheuksfinancialaccounts/2020-07-03> [Accessed 19 September 2021].

Pérignon, C. and Smith, D.R. (2010). Diversification and value-at-risk. Journal of Banking \& Finance, 34(1), 55-66.

Pritsker, M. (1997). Evaluating value at risk methodologies: accuracy versus computational time. Journal of Financial Services Research, 12(2), 201-242.

Rockafellar, R.T. and Uryasev, S. (2000). Optimization of conditional value-at-risk. Journal of risk, 2, 21-42.

Rudd, K. (2009). The global financial crisis. Monthly, The, Feb., 20-29.

Sarma, M., Thomas, S. and Shah, A. (2003). Selection of Value-at-Risk models. Journal of Forecasting, 22(4), 337-358.

Saunders, A. and Allen, L. (2010). Credit risk management in and out of the financial crisis: new approaches to value at risk and other paradigms (Vol. 528). John Wiley \& Sons.

Stambaugh, F. (1996). Risk and value at risk. European Management Journal, 14(6), 612-621.

Strong, R.A., Steiger, N.M. and Wilson, J.R. (2009). December. Introduction to financial risk assessment using Monte Carlo simulation. In Proceedings of the 2009 Winter Simulation Conference (WSC), 99-11, IEEE.

Swamy, V. (2014). Testing the interrelatedness of banking stability measures. Journal of Financial Economic Policy, 6(1), 25-45. 
Tracey, M. (2007). A VAR analysis of the effects of macroeconomic shocks on banking sector loan quality in Jamaica. Available from internet: http://boj. org. jm/uploads/pdf/papers_pamphlets/papers_pamphlets_A_VAR_Analysis_of_ the_Effects_of_Macroeconomic_Shocks_on_Banking_Sector_Loan_Quality. pdf.

Woods, M., Dowd, K. and Humphrey, C. (2008). The value of risk reporting: a critical analysis of value-at-risk disclosures in the banking sector. International Journal of Financial Services Management, 3(1), 45-64. 


\section{Appendix 1: Simulated Values Using Historical Simulation Method}

\begin{tabular}{|c|c|c|c|c|c|c|c|c|c|c|c|c|c|c|c|}
\hline $\begin{array}{c}\text { Date } \\
(d d / m m / y y y y)\end{array}$ & Asset 1 & $\begin{array}{c}\text { Asset Price } \\
\text { Asset } 2 \\
\end{array}$ & $\begin{array}{l}\text { (Daily cl } \\
\text { Asset } 3 \\
\end{array}$ & $\begin{array}{c}\text { sing price) } \\
\text { Asset } 4\end{array}$ & Asset 5 & $\begin{array}{l}\text { Returns } \\
\text { Asset } 1 \\
\end{array}$ & $\begin{array}{c}\text { Asset } \\
2 \\
\end{array}$ & $\begin{array}{c}\text { Asset } \\
3 \\
\end{array}$ & $\begin{array}{c}\text { Asset } \\
4 \\
\end{array}$ & $\begin{array}{c}\text { Asset } \\
5 \\
\end{array}$ & $\begin{array}{c}\text { Portfolio } \\
\text { change }\end{array}$ & $\begin{array}{c}\text { Ascend. } \\
\text { order }\end{array}$ & $\begin{array}{c}\text { No } \\
\text { of } \\
\text { obs. }\end{array}$ & $\begin{array}{c}\text { VaR } \\
\text { (historic) } \\
\end{array}$ & $\begin{array}{c}\mathrm{VaR} \\
\text { at } 99 \% \\
\end{array}$ \\
\hline $2020-01-10$ & 171.54 & 539.40 & 668.41 & 54.26 & 220.18 & & & & & & & & & - & - \\
\hline $2020-01-13$ & 172.18 & 545.12 & 671.61 & 52.83 & 217.10 & 0.00 & 0.01 & 0.00 & -0.03 & -0.01 & 0.00 & -0.01 & 1.00 & -510.19 & \\
\hline $2020-01-14$ & 171.54 & 544.75 & 674.06 & 52.84 & 215.88 & 0.00 & 0.00 & 0.00 & 0.00 & -0.01 & 0.00 & 0.00 & 2.00 & -49.83 & \\
\hline $2020-01-15$ & 169.17 & 544.19 & 661.45 & 52.00 & 210.45 & -0.01 & 0.00 & -0.02 & -0.02 & -0.03 & -0.02 & -0.01 & 3.00 & -1229.70 & \\
\hline $2020-01-16$ & 167.56 & 545.21 & 659.95 & 52.08 & 207.74 & -0.01 & 0.00 & 0.00 & 0.00 & -0.01 & 0.00 & 0.00 & 4.00 & -236.75 & -236.75 \\
\hline $2020-01-17$ & 166.08 & 548.07 & 660.32 & 52.57 & 210.26 & -0.01 & 0.01 & 0.00 & 0.01 & 0.01 & 0.00 & 0.01 & 5.00 & 546.91 & \\
\hline $2020-01-20$ & 165.85 & 546.59 & 657.88 & 52.08 & 208.39 & 0.00 & 0.00 & 0.00 & -0.01 & -0.01 & -0.01 & 0.00 & 6.00 & -496.05 & \\
\hline 2020-01-21 & 165.28 & 540.32 & 649.98 & 52.62 & 210.26 & 0.00 & -0.01 & -0.01 & 0.01 & 0.01 & 0.00 & 0.00 & 7.00 & -87.56 & \\
\hline $2020-01-22$ & 165.62 & 536.26 & 648.10 & 52.25 & 208.39 & 0.00 & -0.01 & 0.00 & -0.01 & -0.01 & 0.00 & -0.01 & 8.00 & -528.29 & \\
\hline $2020-01-23$ & 162.53 & 528.69 & 640.01 & 51.63 & 205.02 & -0.02 & -0.01 & -0.01 & -0.01 & -0.02 & -0.01 & -0.01 & 9.00 & -1100.32 & \\
\hline $2020-01-24$ & 164.37 & 534.60 & 647.91 & 52.25 & 209.05 & 0.01 & 0.01 & 0.01 & 0.01 & 0.02 & 0.01 & 0.01 & 10.00 & 1095.24 & \\
\hline $2020-01-27$ & 161.76 & 515.87 & 618.56 & 51.37 & 204.09 & -0.02 & -0.04 & -0.05 & -0.02 & -0.02 & -0.03 & -0.02 & 11.00 & -2460.87 & \\
\hline $2020-01-28$ & 163.03 & 523.80 & 622.70 & 51.84 & 203.90 & 0.01 & 0.02 & 0.01 & 0.01 & 0.00 & 0.01 & 0.01 & 12.00 & 605.07 & \\
\hline 2020-01-29 & 163.03 & 522.51 & 621.01 & 51.72 & 206.71 & 0.00 & 0.00 & 0.00 & 0.00 & 0.01 & 0.00 & 0.00 & 13.00 & 121.01 & \\
\hline $2020-01-30$ & 162.53 & 519.47 & 611.04 & 52.10 & 207.27 & 0.00 & -0.01 & -0.02 & 0.01 & 0.00 & 0.00 & 0.00 & 14.00 & -237.35 & \\
\hline
\end{tabular}


Appendix 2: Simulations Using The MCS Method

\begin{tabular}{|r|r|r|r|r|}
\hline No of obs & Rand() & NORMSINV() & $(\mu \Delta t+\sigma e V \Delta t)$ & $\Delta S$ \\
\hline 1983 & 0.586409273 & 0.218317866 & 0.004734082 & 473.4081534 \\
\hline 1984 & 0.799420348 & 0.839552565 & 0.020211116 & 2021.111567 \\
\hline 1985 & 0.275177419 & -0.597228495 & -0.015583906 & -1558.3906 \\
\hline 1986 & 0.5103022 & 0.025826657 & $-6.15183 \mathrm{E}-05$ & -6.151828192 \\
\hline 1987 & 0.30459476 & -0.511230707 & -0.013441413 & -1344.141347 \\
\hline 1988 & 0.326618485 & -0.449269898 & -0.011897763 & -1189.77625 \\
\hline 1989 & 0.97742792 & 2.003308733 & 0.049204174 & 4920.417413 \\
\hline 1990 & 0.320182373 & -0.467188883 & -0.012344184 & -1234.418435 \\
\hline 1991 & 0.434702974 & -0.164413104 & -0.004801027 & -480.102702 \\
\hline 1992 & 0.128584016 & -1.133110072 & -0.028934508 & -2893.450842 \\
\hline 1993 & 0.259583633 & -0.644629574 & -0.016764825 & -1676.482543 \\
\hline 1994 & 0.241877291 & -0.7002766 & -0.018151179 & -1815.117895 \\
\hline 1995 & 0.370495611 & -0.330540995 & -0.008939828 & -893.9828406 \\
\hline 1996 & 0.848706765 & 1.030902658 & 0.024978286 & 2497.828648 \\
\hline 1997 & 0.291161706 & -0.549994114 & -0.01440714 & -1440.71396 \\
\hline 1998 & 0.368680311 & -0.335350607 & -0.009059652 & -905.9651928 \\
\hline 1999 & 0.234322422 & -0.72468574 & -0.018759292 & -1875.929228 \\
\hline 2000 & 0.1750094 & -0.934552824 & -0.023987783 & -2398.778327 \\
\hline & & & & \\
\hline
\end{tabular}


Appendix 3: Calculation of Random Numbers and Opposite of Cumulative Uniform Normal Distribution

\begin{tabular}{cc}
\hline Rand() & NORMSINV() \\
& \\
0 & 0 \\
0.706944402 & 0.544480018 \\
0.596096814 & 0.243256924 \\
0.006252555 & -2.497560568 \\
0.323559097 & -0.457769301 \\
0.248789222 & -0.678304818 \\
0.058815251 & -1.564797057 \\
0.806395516 & 0.864689984 \\
0.958605563 & 1.73472868 \\
0.154058525 & -1.019180989 \\
0.345275096 & -0.398108523 \\
0.837373792 & 0.983721599 \\
0.462883762 & -0.093171238 \\
0.440084666 & -0.15075456 \\
0.132245142 & -1.115840806 \\
0.909949298 & 1.340442875
\end{tabular}

